Jochen Schultheiß

\title{
Vom Meißel zum Griffel: \\ Literarisierte Memorialkultur in den \\ Epitaphien des Gregor von Nazianz
}

\section{Materialität - Literarizität - Intermedialität}

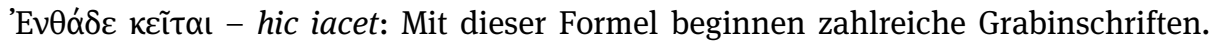
Hierbei lassen die Eingangsworte bereits wesentliche Charakteristika des Epitaphiums als einer Untergattung des Epigramms erkennen: Der Text gibt einen Sprechakt im Hier und Jetzt des Lesers wieder. Dies implizieren das deiktische Adverbial des Or-

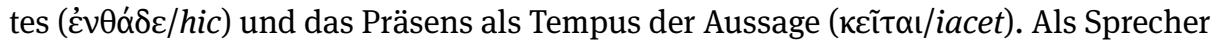
ist das Grab oder ein anonymer Trauernder zu denken. Was passiert aber nun, wenn solche Gedichte in einer Textsammlung erscheinen und damit aus ihrem ursprünglichen Darbietungskontext heraus- und von ihrer materiellen Basis losgelöst werden? Welche Konsequenzen resultieren aus dem Übergang von einer realen zu einer fiktiven Lesesituation am Grab, wenn ein Gedicht dieser Art von einem Leser oder einer Leserin $^{1}$ im Textgefüge einer Gedichtsammlung rezipiert wird? Mit solchen Prozessen gehen Änderungen in der Funktionsbestimmung von Texten einher. Bei der Differenz von Steinepigramm und Buchepigramm erweist sich insbesondere die Überführung einer Inschrift als Einzeltext in den Kontext einer aus einer Vielzahl an Gedichten bestehenden literarischen Sammlung als folgenreich.

Vorab verlangt jedoch die gängige und scheinbar klare Unterscheidung zwischen ,inschriftlich` und ,literarisch` eine genauere Bestimmung. Die Zuschreibung von Literarizität an Texte wird in der Regel an einem als literarisch zu qualifizierenden Niveau, das auf Stilistik und Lexik beruht, festgemacht. Als literarisch gilt ein Text, der eine ästhetische Formung erkennen lässt und dessen Zielsetzung über die bloße Vermittlung von Sachinformationen hinausgeht. Zudem wird gerade bei der antiken Literatur die Allusivität von Texten, das heißt ihre durch intertextuelle Anspielungen hergestellte Selbsteinordnung in die Traditionslinien schriftstellerischen Schaffens, als ein zentrales Element betrachtet, das Literarizität konstituiert. ${ }^{2}$

\footnotetext{
1 Im Folgenden wird aus pragmatischen Gründen die maskuline Form verwendet. Grundsätzlich kann jedoch für die Spätantike von einem hohen Alphabetisierungsgrad bei Frauen ausgegangen werden, so dass auch diese stets als impliziter Adressat(inn)enkreis mitbedacht werden sollten (vgl. Schultheiß 2011, 30-33, 198-200, 242, 250, 261, 281).

2 Vgl. Agosti 2008, der die Literarizität von inschriftlichen Epitaphien in dem intellektuellen Anspruch ausmacht, der von einem Text an den Leser gestellt wird; ferner resümierend Agosti 2010b, 349.
}

Ә Open Access. (C) 2019 Jochen Schultheiß, publiziert von De Gruyter. (c) BY-NC-ND Dieses Werk ist lizenziert unter der Creative Commons Attribution-NonCommercial-NoDerivatives 4.0 Lizenz. 
Jedoch lässt sich bereits für das archaische und klassische griechische Epigramm eine Beeinflussung durch andere literarische Gattungen und eine zunehmende Komplexität in der formalen und sprachlichen Gestaltung festhalten. ${ }^{3}$ Eine Rückwirkung von Buchepigrammen auf Steinepigramme ist spätestens seit dem Hellenismus zu beobachten. ${ }^{4}$ Dies gilt umso mehr für die Spätantike, in der die Literaturform des Epigramms und hierin inbegriffen die des Epitaphs schon auf eine lange literarische Tradition zurückblicken können. Auch epigraphische Grabinschriften wurden nicht selten von professionellen Dichtern angefertigt. ${ }^{5}$ Sie konnten durchaus eine sehr kunstvolle Gestaltung vorweisen und dabei einen nicht geringen Bildungsanspruch an den Leser stellen. Der grundlegenden Definition von Literatur, wonach ein Text ästhetische Ansprüche erfüllen muss und nicht bloß der Weitergabe einer Information dienen darf, können somit auch inschriftlich überlieferte Epitaphien vollends gerecht werden. Ebenso sind Anspielungen auf literarische Prätexte bei zahlreichen Steinepigrammen feststellbar. ${ }^{6}$ Diese Beobachtung kann man gerade in der Spätantike machen, die von einem markanten Zuwachs an Inschriften, sei es in Versen oder in Prosa, gekennzeichnet ist. Dabei wird die quantitative Entwicklung in dieser Epoche auch von einer Steigerung der literarischen Qualität der Inschriften begleitet. ${ }^{7}$

Da nun auch Steinepigramme häufig kunstvoll gestaltet waren und zudem ursprünglich epigraphische Gedichte nachträglich in eine Textsammlung aufgenommen werden konnten, ${ }^{8}$ dienen innertextuelle Charakteristika wie Stil und Sprache höchstens als relative Differenzierungskriterien zwischen inschriftlichen und literarischen Epigrammen.

Somit rückt als wesentliches Unterscheidungsmerkmal zwischen den beiden Formen ein anderes, außertextuelles Element in den Blickpunkt: die Materialität des Textträgers, auf dem ein Leser das Gedicht rezipiert. Diese bestimmt in entscheidendem Maße über das Bedeutungspotential, das die Gedichte entwickeln können. Mag es nun sein, dass es auch Steinepigramme gibt, die sich durch allusive Bezugnahmen in die literarische Tradition einzureihen versuchen, darf dennoch festgehalten werden, dass Buchepigramme aufgrund ihrer materiellen Gegebenheit eine deutliche Erweiterung ihres Kontextes erfahren. Sie finden sich eingeordnet in ein Ensemble von Gedichten, das im Leser bei einer seriellen Lektüre bestimmte Assoziationen erwecken kann. ${ }^{9}$ Umgekehrt braucht bei ihnen der Zweck, dass sie zur Herstellung der

3 Vgl. zusammenfassend Meyer 2005, 107.

4 Vgl. Meyer 2005, 36. Bettenworth 2007 weist für das hellenistische Epigramm auf gebotene Differenzierungen je nach der Richtung der Beeinflussung hin.

5 Vgl. Garulli 2012, 389-391.

6 Für den lateinischen Bereich Wolff 2000, 102-104.

7 Vgl. Agosti 2015, 13.

8 So etwa Asper 2004, 46, über die Epigramme des Kallimachos.

9 Zur Wirkung der seriellen Lektüre von Epigrammen auf den Leser vgl. Harich-Schwarzbauer 2009. 
Erinnerung an eine konkrete Person beitragen sollen, keine Rolle mehr zu spielen. ${ }^{10}$ Durch die Lösung der Texte von ihrer materiellen Basis sind die Epigramme von ihrer ursprünglichen Funktion befreit, müssen also nicht mehr dem Totengedenken oder der Weihe dienen, vielmehr können sie nun mit jedem beliebigen Inhalt gefüllt werden. Die Loslösung führt im Hellenismus bis zur Entstehung von Epigrammen sympotisch-erotischen Inhalts. ${ }^{11}$ Zudem sind beim literarischen Epigramm im Hellenismus die Anlässe meist fiktiv. ${ }^{12}$

Ein klareres Bild ergibt sich somit, wenn man den Blick ganz gezielt auf den Aspekt der Intermedialität lenkt. das heißt, auf den Medien- oder Materialwechsel von Stein auf Papier oder Pergament, und auf die Folgen, die dieser insbesondere durch die Ensemblebildung von Gedichten mit sich bringt. Dann werden durchaus sehr deutliche Unterschiede zwischen den inschriftlichen und den in Textkorpora aufgenommenen oder sogar eigens für solche verfassten Epitaphien greifbar. ${ }^{13}$ Der Leser des Buchepigramms nimmt ein Gedicht im Kontext der in der Papyrusrolle oder im Buch enthaltenen Werke wahr. Er hat die Möglichkeit zurückzugehen, vorauszublicken und Vergleiche anzustellen. ${ }^{14}$ Die Einfügung in ein Ensemble von Texten und die daraus resultierende Intertextualität eröffnet neue Bedeutungsebenen, die dem gewöhnlich als Einzelgedicht belegten Grabepigramm gänzlich abgehen.

Kathryn Gutzwiller hat aufgezeigt, dass bereits im hellenistischen Epigrammbuch Gedichte so zusammengestellt werden, dass für den Leser ein einheitliches Bild vom Dichter entsteht. ${ }^{15}$ Der Autor kann hierbei davon ausgehen, dass der Leser bereits durch die Darbietung des Epigramms in einer Textsammlung auf eine Form der Interpretation eingestellt ist, wie er sie aus literarischen Werken kennt. Beim Leser liegt generell eine Tendenz vor, Aussagen einzelner Gedichte in der Interpretation zusammenzuführen und einen einheitlichen Sinn herzustellen. Die Dichter ihrerseits arbeiten einer solchen Rezeptionshaltung entgegen. ${ }^{16}$ Das Plus an Bedeutung, das die Epigramme innerhalb einer Sammlung erhalten, braucht somit nicht erst durch den Leser generiert zu werden, sondern kann bereits Teil eines Programms sein, das der Dichter bewusst verfolgt.

Die sicherlich weitreichendste Form der Literarisierung einer Gattung stellt ihre ironische Brechung dar. Diese ist gerade beim Grabepigramm überhaupt nur unter

10 Die Selbstzweckhaftigkeit wird bereits bei Reitzenstein 1907, 81-82 als Kennzeichen des literarischen Buchepigramms herausgestellt.

11 Vgl. Meyer 2005, 107-108.

12 Vgl. Degani 1997, 1110.

13 Hiermit reiht sich die vorliegende Untersuchung innerhalb einer weiter gefassten Intermedialitätsforschung in den Bereich ein, der insbesondere die Folgen eines Medienwechsels für die Entwicklungsgeschichte einer literarischen Gattung zu seinem Gegenstand macht. Zu einer systematischen und forschungsgeschichtlichen Einordnung am Beispiel des Briefgenres vgl. Wulfram 2008, 36-51.

14 Vgl. Meyer 2005, 5-6.

15 Vgl. Gutzwiller 1998, 7, 11-12, 28-30, 52-53.

16 Dies hat Schmitz 2010 am Beispiel der kallimacheischen Epigramme aufgezeigt. 
der Voraussetzung einer Loslösung aus dem eigentlichen Darbietungskontext und von der ursprünglichen materiellen Basis denkbar. Denn eine Ironisierung steht dem Totengedenken diametral entgegen. Eine entsprechende Transformation der Gattung, bei der sie eine satirische Stoßrichtung erhält, setzt bereits mit Kallimachos (zwischen 320 und 303 v. Chr. - nach 246 v. Chr.) ein. Ein Beispiel stellt das Epigramm auf den Philosophen Kleombrotos von Ambrakia dar (Call. Epigr. 53 Asper = 23 Pf.). Dieser begeht in voreiligem Vertrauen auf die platonische Lehre von der Unsterblichkeit der Seele Suizid. ${ }^{17}$ Insbesondere die Einfügung eines Epitaphs in eine heterogene Sammlung von Epigrammtypen fördert die ironische Lesart. Als Beispiel aus der lateinischen Spätantike kann Gedicht 11 in Claudians Carmina minora angeführt werden, das sich als ein Spottepigramm auf die verblichene Schönheit einer Frau liest. ${ }^{18}$ Hierbei wird das Epitaphium als formales Substrat mit dem Inhalt satirischer Verunglimpfung gefüllt, die sich sehr häufig gegen einen Typus von Person wendet ${ }^{19}$ und zu deren topischem Themenarsenal Alterungserscheinungen wie der Zerfall äußerer Schönheit gehören. ${ }^{20}$ Eine ironische Lesart wird hierbei durch die Kontextualisierung des Epitaphs innerhalb der Epigrammsammlung unterstützt. So enthalten in unmittelbarer Nähe auch die carmina 10, 15 und 16 humorvolle Figurentypik. ${ }^{21}$ Hierdurch wird die Möglichkeit einer für den konkreten Anlass verfassten Gelegenheitsdichtung, also die eines ernstgemeinten Grabepigramms, endgültig unwahrscheinlich. Ironische Gedichte evozieren in der Fiktion die ursprüngliche Darbietungssituation des Grabepigramms, werden jedoch aufgrund bizarrer inhaltlicher Kontraste, die innerhalb des Gedichts sowie durch den Kontext der Sammlung entstehen, zu scherzhaft-spöttischen Epigrammen. Hierbei wird deutlich, dass überhaupt erst die Loslösung aus dem eigentlichen Darbietungskontext die ironische Wendung einer Gattung wie des Grabepigramms erlaubt. Mag die gesellschaftliche Beurteilung des Todes kultureller Relativität und somit dem Wandel unterliegen, mögen hier und da auch humorvolle

17 Hierzu Asper 2004, 47: „53 erzählt einen philosophischen Selbstmord mit einem Augenzwinkern.“ 18 Claud. carm. min. 11: In Sepulchrum speciosae: / Pulchris stare diu Parcarum lege negatur. / Magna repente ruunt; summa cadunt subito. / Hic formosa iacet: Veneris sortita figuram / egregiumque decus invidiam meruit. (,Auf das Grab einer Schönen: Dem Schönen ist es durch das Gesetz der Parzen verboten, lange zu bestehen. Das Große stürzt mit einem Schlag ein; das Bedeutendste fällt sofort. Hier liegt eine Schöne begraben; sie hat, nachdem sie die Gestalt und den herausragenden Reiz der Venus erlost hatte, sich deren Missgunst zugezogen.“ Textgestalt nach Hall 1985, Interpunktion nach der überzeugenderen Setzung bei Sklenář 2003).

19 Vgl. Holzberg 2012, 85-86.

20 In skurriler Weise setzen Lucan-Zitate den physiologischen Niedergang des Aussehens dem absteigenden Prozess innerhalb eines zyklischen Geschichtsbildes gleich. Lucans in se magna ruunt (Lucan.1,82) findet sich in magna repente ruunt wieder. Der Vers invida fatorum series summisque negatum/ stare diu aus dem Epos (Lucan.1,70-71) erscheint in pulchris stare diu. Die fata sind durch die lex Parcarum ersetzt, und in beiden Gedichten wird Erfolg zum Opfer von Missgunst: invida fatorum series bei Lucan, invidia bei Claudian. Statt von den fata kommt bei dem spätantiken Dichter die invidia jedoch von Seiten einer in ihrer Eitelkeit gekränkten Venus.

21 Nummerierung nach Hall 1985. 
Elemente auf Grabsteinen anzutreffen sein, ${ }^{22}$ spöttische Gedichte auf Verstorbene findet man auch auf antiken Gräbern nicht.

Wenn wir die anfangs gestellte Frage nach der Bestimmung der Literarizität von Epitaphien wieder aufnehmen, dann zeigt sich hier, dass die Intermedialität, die sich in der Loslösung einer Gedichtform von ihrer materiellen Basis und aus ihrem ursprünglichen Darbietungskontext sowie in der damit einhergehenden Überführung in eine Textsammlung vollzieht, das wesentliche Kriterium darstellt, das ein literarisches von einem inschriftlichen Epitaph unterscheidet. Dabei bleiben durchaus einige konstitutive Elemente der Textgattung des Epitaphs, die untrennbar mit der Materialität der Inschrift verknüpft sind, auch in den dichterischen Grabepigrammen erhalten. Insbesondere die imaginierte Kommunikation zwischen dem Verstorbenen oder dem Stein selbst, die als Sprecher fungieren, und dem Passanten oder Betrachter als Adressaten liegt auch der literarischen Form des Grabgedichts zugrunde. Aus der realen Lesesituation wird nun jedoch eine fiktive, ${ }^{23}$ in der sich dem Leser des Buchepigramms infolge seiner Kontextualisierung in einer Gedichtsammlung ganz neue Bedeutungspotentiale eröffnen, die einem inschriftlichen Epitaph als Einzelgedicht grundsätzlich verwehrt sind.

Soviel zur gattungsgeschichtlichen Entwicklung des Epitaphiums, in die sich die Gedichte des Gregor von Nazianz einordnen. Wie gestaltet nun Gregor seine Grabepigramme, nachdem sich eine Tradition der Gedichtsammlung ausgebildet hat, in der die kleinen Gattungen der Gelegenheitsdichtung nicht mehr unbedingt ihre ursprünglichen Funktionen erfüllen müssen?

\section{Gregor von Nazianz: Epitaphien}

Gregor von Nazianz (ca. 329/30 - ca. 390) steht mit seinem vielseitigen poetischen Werk in der zweiten Hälfte des 4. Jahrhunderts am Beginn einer neu einsetzenden Blütephase der griechischen Dichtung. ${ }^{24}$ In seinen Carmina rechtfertigt er sein poetisches Wirken, indem er sich zum Ziel setzt, ein christliches Pendant zur paganen Dichtung zu schaffen. ${ }^{25}$ Somit sind auch Gregors Epigramme im Kontext der christ-

22 Vgl. Wolff 2000, 127-128 zu einem Beispiel (CLE 484) sowie S.15 und 104-106 zum Wortspiel der Paronomasie. Hier dient Humor dem Ausdruck eines zur Lebensmaxime erklärten Diesseitsgenusses. 23 In dieser Fiktion besteht nun eine Trennung zwischen dem fiktiven Leser, d. h. dem imaginierten Leser des Grabsteins, den der Sprecher anredet, und dem implizierten Leser, der vom Autor als Leser des Buches angesprochen wird. Zu dieser Unterscheidung bei Kallimachos vgl. Gutzwiller 1998, 196. 24 Zur Einordnung der Dichtung des Kirchenvaters in den Kontext der spätantiken griechischen Literatur vgl. Agosti 2010a, 163.

25 Z. B. Greg. Naz. carm. 2,1,39,47-51; vgl. zu Gregors Konzeption der Zusammenführung von traditioneller Bildung und christlichem Glauben Wyss 1949, 179-186. 


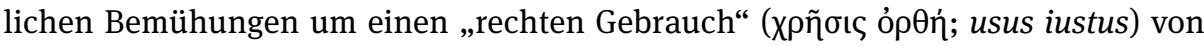
paganen Bildungsgütern zu betrachten. ${ }^{26}$

Im Codex Palatinus Graecus 23, der die bunte Gedichtsammlung der Anthologia Palatina überliefert, ist das je nach Zählung aus 254 oder 256 Epigrammen bestehende Buch 8 mit dem Titel überschrieben „Aus den Dichtungen des Heiligen Gregor des Theologen““. ${ }^{27}$ Das Buch beinhaltet in erster Linie Epitaphien, wodurch es gattungstypologisch an das vorausgehende 7. Buch der Anthologia Palatina anschließt, das zumeist Werke älterer und paganer Autoren umfasst. Die Epigramme 1-165 stellen Grabepigramme auf einzelne Personen dar. Die Sammlung der Epitaphien ist nach den einzelnen verstorbenen Personen gegliedert, auf die sie verfasst sind. Die so in Gruppen zusammengestellten Gedichte sind wiederum nach absteigender Versanzahl angeordnet. Auf die Epitaphien folgen ebenfalls der Sepulkraldichtung zuzuordnende Epigramme, die von der zeittypischen Gewohnheit, Gastmähler an den Gräbern zu feiern, abhalten oder Grabräuber abwehren sollen. Diese unterscheiden sich in ihrer Machart grundsätzlich und verdienen deshalb, eigenständig untersucht zu werden. ${ }^{28}$ Gregors Epitaphien sind Personen aus dem engeren Verwandten- und Vertrautenkreis gewidmet. Hierzu gehören sein Vater und insbesondere seine Mutter, ferner der Bruder, die Schwester, Cousins, der Schwager, der Onkel, aber auch der enge Freund Basileios von Kaisareia (Basileios der Große) und andere Personen aus dem politischen und kirchlichen Leben, vornehmlich aus Gregors Heimat Kappadokien.

Auffallend ist die Tatsache, dass häufig eine Vielzahl von Epitaphien auf eine Person verfasst ist: 12 auf den Vater, 17 auf den Bruder Kaisarios, 10, je nach Zählung 11 auf Basileios, weitere auf andere Verwandte oder bedeutende Figuren des zeitgenössischen geistigen Lebens und 53 - die größte Gruppe - auf die Mutter Nonna. Acht Gedichte sind sogar Epitaphien auf Gregor selbst. Die Gedichte 75 und 76 stellen Abschiedsgedichte der verstorbenen Eltern an ihren Sohn dar. Die Anordnung in Gruppen entsprechend einzelner Personen geht mit sehr großer Wahrscheinlichkeit auf eine frühere Textsammlung Gregors zurück, da diese Gliederungsstruktur nicht derjenigen der anderen Bücher der Anthologia Palatina entspricht. ${ }^{29}$ Hieraus lässt sich auf ein individuell gestaltetes Substrat schließen. Dabei wird die Vermutung, dass die Anordnung auf einer vorausgehenden Gedichtsammlung Gregors beruht, von der entstehungsgeschichtlichen Analogie zu anderen Epigrammzyklen innerhalb der Anthologia Palatina gestützt, für die sich ebenfalls glaubhaft machen lässt, dass sie von

26 Vgl. Gnilka 2012, 113-116 speziell zu den Belegstellen bei Gregor von Nazianz.

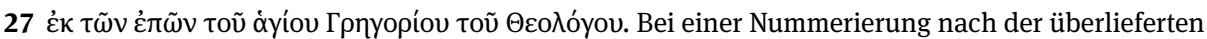
Textgestalt umfasst das Buch 254 Epigramme, jedoch bilden 67 und 85 jeweils zwei Gedichte. Beckby 1957 zählt 254 Epigramme, Cameron 1993, 107 und 145 (unter Betonung der Problematik der Teilung von Gedichten) 260 Werke.

28 Eine solche Analyse wurde von Floridi 2013 unternommen.

29 Für einen Überblick über die Systematik der Epitaphien Meleagers im 7. Buch der Anthologia Palatina vgl. Tafel 5 in Gutzwiller 1998, 330-331. 
älteren Zusammenstellungen der Werke einzelner Autoren abhängig sind. ${ }^{30}$ Somit ist es durchaus plausibel, dass die Gedichtsammlung nicht erst postum von Freunden erstellt wurde, wie vermutet wurde. ${ }^{31}$ Vielmehr ist davon auszugehen, dass bereits Gregor an die Idee der Gedichtsammlung anzuschließen versucht, die bis zum Hellenismus zurückverfolgt werden kann. ${ }^{32}$ Wie bereits die hellenistischen Epigrammdichter geht hierbei auch Gregor von einem Leser aus, der die Gedichte als literarische, nicht inschriftliche Produkte liest.

Die Tatsache, dass für einzelne Personen eine größere Anzahl an Epitaphien verfasst wurde, lässt unweigerlich Zweifel daran aufkommen, dass die Grabgedichte tatsächlich für ihre eigentliche Bestimmung, die Anbringung an einem konkreten Grab, abgefasst wurden. Mögen auch Inschriftenfunde belegt sein, bei denen mehrere Epitaphien die verschiedenen Seiten eines Grabmals schmücken, so lässt die ungewöhnlich hohe Zahl an Epigrammen auf einzelne Personen bei Gregor diese Erklärung nicht zu. ${ }^{33}$ Man könnte nun die Vermutung anstellen, dass Gregor zunächst mehrere Gedichte abgefasst habe, um dann das gelungenste für eine Anbringung am Grab auswählen zu können, dass es schließlich aber zu einer unbeabsichtigten Veröffentlichung aller Entwürfe gekommen sei. Eine solche Annahme wird jedoch durch die Aussage in epitaph. 30 ausgeschlossen, worin der Sprecher explizit äußert, dass er die Verehrung seiner Mutter durch eine solch große Menge an Gedichten zum Ausdruck habe bringen wollen (Greg. Naz. epitaph. 30,4-6), ebenso wie durch die Beteuerung in einem Epitaph auf Basileios, für diesen ein Duzend Epitaphien angefertigt zu haben (Greg. Naz. epitaph. 11b). ${ }^{34}$ Dies spricht für die systematische Zusammensetzung allmählich entstandener Gedichte, wenn nicht sogar für die Komposition geschlossener Zyklen. Die Vielzahl von Epigrammen auf eine Person kann auch für Kallimachos mit seinen acht Epitaphien auf Timon als Ausweis des literarischen Charakters gelten (AP 7,313-320).

Auf die Literarizität der Werke deuten zudem die Grabgedichte hin, die Gregor auf sich selbst verfertigt. ${ }^{35}$ Auch diese Praxis hat eine namhafte Tradition seit Kallimachos. ${ }^{36}$ Daneben können auch die dem eigenen Vater gewidmeten Epitaphien (Greg.

30 Vgl. Gutzwiller 1998, 321-322 (zusammenfassend zu Meleager).

31 So etwa Beckby 1957, 446-447.

32 Die noch bei Degani 1997, 1111 vertretene, in sich selbst schon widersprüchliche Auffassung, wonach es sich beim 8. Buch der Anthologia Palatina um eine „ehrgeizige und wirre Produktion“ handle, darf somit als überwunden gelten.

33 Wohl als Maximalzahl bei den lateinischen Inschriften anzusehen sind die sieben des Cassius Philippus auf seine Frau Atilia Pomptilla, vgl. Wolff 2000, 42; ferner Gutzwiller 1998, 229. Zu den literarischen Beispielen der Gedichtpaare AP 7,327-328, 334-335, 679-680 vgl. Waltz 1960, 25.

34 Vgl. Consolino 1987, 411.

35 Epitaph. 79-84.

36 Es ist in der literarischen Tradition nicht ungewöhnlich, dass ein Autor Epitaphien auf sich selbst verfasst. Call. Epigr. 35 Pf. (= AP 7,415) war wohl weniger als Grabepigramm für den Dichter selbst gedacht als vielmehr als Selbstvorstellung im Kontext einer Gedichtsammlung (vgl. hierzu Meyer 2005, 
Naz. epitaph. 12-23) auf eine Vorgeschichte zurückblicken. ${ }^{37}$ Wie bei Kallimachos steht auch bei Gregor in den Epitaphien auf den Vater nicht dieser, sondern der Sohn im Mittelpunkt des Interesses. Das indirekte Lob des Autors auf sich selbst stellt ein literarisches Mittel dar, über sich selbst zu schreiben, hierbei aber das dem christlichen Bescheidenheitsgebot widersprechende Eigenlob zu umgehen. ${ }^{38}$

Ein ganz dezidierter Hinweis auf die Literarizität eines Epigramms liegt dann vor, wenn sich der Sprecher in seiner Funktion als Autor thematisiert und dabei seinen Schreibakt reflektiert. So etwa in epitaph. 160:

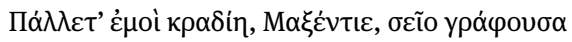
oüvo $\mu \alpha[\ldots]$.

Es pocht mir das Herz, wenn es deinen Namen schreibt [...]. ${ }^{39}$

(Greg. Naz. epitaph. 160)

Eine solche Schilderung des Schreibvorganges, der hier metaphorisch als Tätigkeit des Herzens dargestellt ist, wäre bei einer Inschrift, die man von einem Steinmetz eingemeißelt denken muss, gänzlich unpassend.

Entstehungsgeschichtliche Erklärungen, wonach Gregor einzelne Epigramme an je verschiedene Adressaten geschrieben und versandt hat, können nicht ausgeschlossen werden, treten jedoch hinter die begründete These einer zur Edition bestimmten Gedichtsammlung zurück. Ebenso zeigt sich, dass unterschiedliche formale Gestaltungsweisen verschiedene inhaltliche Gesichtspunkte beleuchten, so dass die Variation sicherlich nicht nur als das Resultat einer imitatio-Technik zu erklären ist, die auf die Nachahmung eigener Gedichte ausgerichtet wäre. ${ }^{40}$ Dies soll im Folgenden noch deutlicher werden.

171-172); Weitere Epigramme von Dichtern auf sich selbst finden sich u. a. in AP 7,417-419, 421, 428 (Meleagros); zur hellenistischen Tradition der Selbstepitaphien vgl. Gutzwiller 1998, 44, 85, 108, 271, 276, 286, 299, 308.

37 Zu Kallimachos' fiktionalem Epitaph auf seinen Vater (Epigr. 21 Pf.; AP 7,525) vgl. Gutzwiller 1998, 40, 212.

38 Für die Epitaphien 75, 77, 82, 165 wurde aufgrund des Selbstlobs sogar die Athetese vorgeschlagen (vgl. Beckby 1957, 446).

39 Die griechischen Texte werden nach Beckby 1957 zitiert, sämtliche Übersetzungen sind eigene.

40 Diese Deutung liegt Criscuolo 2007 (49: ,ininterrotto colloquio del poeta con sé stesso“) zugrunde. 


\section{Kommunikative Konstellationen: Verschiedene Sprecher- und Adressatenrollen}

Epigramme geben in der Regel einen fiktiven Sprechakt wieder. ${ }^{41}$ Ein zentrales Merkmal des Epigramms im Allgemeinen sowie des Epitaphiums im Speziellen bildet die große Varietät von möglichen kommunikativen Konstellationen, in denen ein Sprecher seine Worte an einen Adressaten richtet. Erstellt man eine Typologie solcher kommunikativen Situationen bei Gregor und gleicht diese mit dem epigraphischen und literarischen Befund in der Gattungsgeschichte ab, so wird deutlich, dass Gregor sich an der inschriftlichen und der literarischen Tradition orientiert und eine sehr breite Streuung der überlieferten Formen sucht. ${ }^{42}$ So lassen die in Gregors Epitaphien erkennbaren Sprecherpersonen eine Systematisierung zu. In den bei Gregor auszumachenden Kategorien spiegelt sich die große Breite der Sprecherrollen wieder, die sich in der Geschichte des Epigramms ausgeformt hat.

In der historischen Gattungsentwicklung geht mit der Ausbildung unterschiedlicher kommunikativer Situationen und verschiedener Sprecherrollen eine zunehmende Personalisierung des Sprechers einher, das heißt, er wird immer stärker als Subjekt mit psychischen Eigenschaften fassbar. Diese Entwicklung wird bereits nach dem Übergang vom Steinepigramm zum Buchepigramm im Hellenismus deutlich. ${ }^{43}$ Gregor wird diese Tradition um eine nochmals ganz bedeutende Dimension erweitern, indem er als Autor fast durchwegs als Sprecherperson auftritt und die Betrauerten als sein persönliches Umfeld von Familienmitgliedern, Freunden und Vertrauten zu erkennen gibt.

Im Folgenden soll nun der Versuch einer systematisierenden Zusammenstellung der verschiedenen kommunikativen Konstellationen von Sprecher und Adressaten unternommen werden. Hierbei sollen diejenigen Konstellationen erfasst werden, die sowohl in der Gattungstradition des Grabepigramms vorliegen als auch in den Epitaphien Gregors von Nazianz zu finden sind. ${ }^{44}$ Eine ausführliche Übersicht der jeweiligen Belegstellen findet sich in der Tabelle im Anhang:

$41 \mathrm{Zu}$ der generellen Feststellung, dass Epigrammtexte fiktive Inszenierungen von Sprechhandlungen darstellen, vgl. grundlegend Meyer 2005, 8-22. Die unterschiedlichen Sprecherpersonen macht bereits Peek 1955 zum Gliederungsprinzip für Versinschriften.

42 Der Rückgriff Gregors sowohl auf Epigramme der inschriftlichen als auch der literarischen Tradition hat Floridi 2013 für die spezifische Gruppe von Epigrammen nachgewiesen, die sich gegen Grabschänder wenden. In einer solchen Scharnierposition zwischen einer epigraphischen und einer (zwar noch nicht alten, aber dennoch schon vorhandenen) literarischen Gattungsentwicklung der Epigrammdichtung wird bereits Kallimachos positioniert (vgl. Hutchinson 1988, 71).

$43 \mathrm{Zu}$ der fortschreitenden Ausgestaltung des Sprechers als persona vgl. Meyer 2005, 71-72, 223, 262.

44 Ein vergleichbarer Kategorisierungsversuch zu den Epigrammen des Kallimachos wurde bei der Tabellenansicht in Meyer 2005, 148-151 unternommen. 
1. Sprecher: Der anonyme Trauernde / Gregor ${ }^{45}$
a) Adressat: Passant
b) Adressat: Toter
c) Andere spezifische Adressaten
d) Ohne spezifische Adressaten

2. Sprecher: Der / Die Tote / Die Toten

3. Sprecher: Grabmal / Die Erde, die den/die Tote/n bedeckt / Erinnerungsstätte

4. Dialog (mehrere Stimmen):
a) Anonymer Trauernder / Gregor - Die/Der Tote
b) Anonymer Trauernder / Gregor - Grab
c) Anonymer Trauernder (oder Grab) / Gregor - Anonymer Passant
d) Gespräch zwischen Dritten

5. Untergeordneter Sprecher ${ }^{46}$

Die Person des Sprechers erweist sich in inschriftlichen Grabepigrammen in der Regel als das Grab selbst, häufig auch als ein anonymer Trauernder. Neben einer solchen Variabilität bei den Sprecherpersonen lässt das Steinepigramm auch schon eine Dynamik der Erzählperspektive erkennen, wobei neben den transparenten auktorialen Erzähler mit distanziert-neutraler Erzählperspektive der personale tritt, der als individuelles Subjekt fassbar wird. ${ }^{47}$ Im Buchepigramm erhält diese Form durch die herstellbare Identifikation des Sprechers mit dem Autor eine deutlich erweiterte Dimension. ${ }^{48}$ In einer mit einem Autornamen verbundenen Sammlung von Gedichten wird der personale Sprecher, sofern er keine expliziten oder impliziten anderweitigen Hinweise gibt, mit dem Autor identifiziert (1). ${ }^{49}$ Der Sprecher gibt Auskunft über den Toten im Anblick des Grabes. Als Adressaten des anonymen Trauernden / Gregor fungieren angesprochene anonyme Passanten (1a). ${ }^{50}$ Der Sprecher kann jedoch auch den Toten (1b) oder einen anderen Adressaten (1c) anreden, oder der Adressat kann unspezifisch bleiben (1d). In den Steinepigrammen bleibt ein solcher informierender Sprecher in der Regel anonym. ${ }^{51}$ Bei dieser Sprecherperson sind auch verschiedene Erzählhaltungen festzustellen. Er kann ein zurückhaltender, objektiv informierender Sprecher sein. Es findet sich jedoch auch ein emotional involvierter Sprecher. ${ }^{52}$ Ferner

45 Zum ,anonymen Trauernden' der inschriftlichen und literarischen Tradition vgl. Meyer 2005, 7783. Diese Sprecherrolle wird vom Leser der Epigrammsammlung mit dem Autor Gregor identifiziert.

46 Eine solche „Rede in der Rede“ begegnet auch bei Kallimachos schon häufig; vgl. Meyer 2005, 145. 47 Weiterführend mit Diskussion der betreffenden theoretischen Literatur Meyer 2005, 14-15.

48 Zum personalen Erzähler und zur Identifikation der persona des Sprechers mit dem Autor im Buchepigramm vgl. Meyer 2005, 108-109, 159.

49 Vgl. Meyer 2005, 22.

50 Als Beispiel für eine explizite Anrede sei hier auf Greg. Naz. epitaph. 157,3 verwiesen: $\theta v \eta \tau \varepsilon ́$. 51 Ausnahmen bei der Sprecherperson: Greg. Naz. epitaph. 135 (Heimatstadt Diokaisareia).

52 Z. B. Greg. Naz. epitaph. 2; 51; 85 (auf den Bruder Kaisarios). Der Ausdruck der Abneigung gegenüber dem Grab erfolgt durch das Adjektiv $\sigma \chi \varepsilon \dot{\tau} \lambda ı$ ı an erster Stelle des Gedichts und durch das 
können auch die oder der Tote, oder die Toten selbst, Sprecher sein (2), ${ }^{53}$ und schließlich auch das Grab, die Erde des Grabes oder eine andere Gedenkstätte (3). ${ }^{54}$ In diesem Fall bringt das Grab häufig einen deiktischen Hinweis vor, wie er für die Epigrammdichtung typisch ist. Eine solche mit Zeigerfunktion verbundene Aussage konkreti-

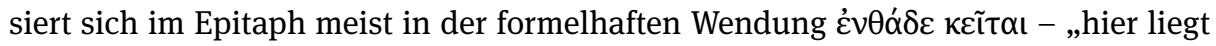
begraben“.

Eine weitere Gruppe stellen Dialoge mit mehreren Sprechern dar (4). Zur Präzisierung ist anzumerken, dass häufig schon eine kommunikative Situation, in der ein Sprecher sich an einen Passanten wendet, ohne dass dieser antworten würde, als dialogisch aufgefasst wird. Damit eine genauere Klassifizierung möglich wird, soll hier jedoch nur dann von Dialog gesprochen werden, wenn mehrere Sprecherstimmen im Text ausgemacht werden können, die miteinander kommunizieren. Diese können ein Gespräch abbilden, das entweder zwischen dem anonymen Trauernden / Gregor und der/dem Toten (4a), dem anonymen Trauernden / Gregor und dem Grab (4b) oder dem anonymen Trauerndem / Gregor oder dem Grab und einem anonymen Passanten $(4 \mathrm{c})^{55}$ oder zwischen Dritten (4d) geführt wird. ${ }^{56}$ Eine weitere Variante stellt die Einfügung eines untergeordneten Sprechers (5) dar, wobei dessen direkte Rede in die Rede des Hauptsprechers implementiert ist. ${ }^{57}$ Bei einigen Sprechertypen können die Epitaphien auch eine stark szenische Situation evozieren. ${ }^{58}$ Die Sprecherperson braucht nicht unbedingt nur ein Individuum zu präsentieren, vielmehr kann in der 1. Person Plural auch eine Personengruppe zu Wort kommen. ${ }^{59}$

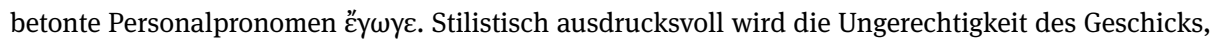

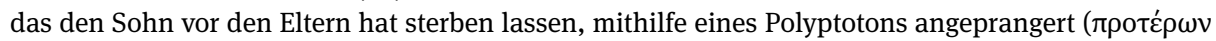
$\pi \rho o ́ \tau \varepsilon \rho o v)$. Ferner ist an die fragende Anrede des Sprechers an den Gestorbenen (142) und an die emotionale Situation des Schreibens (160,1-2) zu denken.

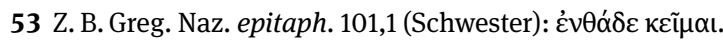

54 Z. B. Greg. Naz. epitaph. 38; Beispiele für Varianten: 136 (Staub des Toten); 137 (Aufruf des Grabs an

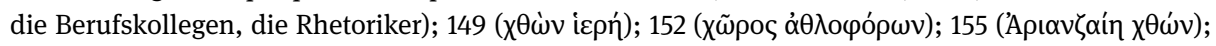
163 (kóvıs).

55 Bei Greg. Naz. epitaph. 126 ist eine klare Zuordnung schwierig.

56 Z. B. Greg. Naz. epitaph. 128 (Chariten und Musen). Nicht zu finden ist bei Gregor die inschriftlich belegte Kommunikation zwischen dem Toten und einem anonymen Passanten: z. B. SGO 01/12/05, ferner I. Métr. 60 (hierzu Agosti 2010a, 165) oder das Epitaph der Arsinoe aus dem 1. Jh. n. Chr. (zu Text und Interpretation vgl. Agosti 2010b, 332).

57 Z. B. Greg. Naz. epitaph. 70 (eingefügte Rede Nonnas), 162 (eingefügte eigene Rede durch das Sprecher-Ich).

58 Greg. Naz. epitaph. 30 (Mutter und zurückkehrender Sohn); 110 (Ausrufe des Entsetzens vom Toten Martinianos, dessen Grab gerade von einem Grabräuber heimgesucht wird).

59 In Greg. Naz. epitaph. 113, einem Lobgedicht auf die Leistungen des Martinianos, wird ein panegyrischer Ton angeschlagen. Als Sprecher erscheint ein anonymes Kollektiv (,wir“), wodurch Martinianos' Bedeutung als öffentliche Person unterstrichen wird. Zu AP 7,517-519, in denen der Sprecher eine Gruppe von Trauernden vertritt, vgl. Gutzwiller 1998, 39. 
In all diesen Variationen greift Gregor sowohl auf geläufige Gestaltungsformen von Epitaphien in Epigrammsammlungen als auch von realen Grabinschriften zurück, so dass bei der Lektüre der Gedichte der Eindruck einer kaleidoskopartigen Zusammenführung sowohl der inschriftlichen als auch der literarischen Gattungstradition entsteht.

\title{
4 Beispielhafte Epigrammzyklen
}

Betrachten wir zunächst den Zyklus auf seinen Freund Basileios von Kaisareia, der die Epitaphien 2 bis 11 umfasst. Im ersten Gedicht dieses Zyklus (Greg. Naz. epitaph. 2) ist Gregor als Sprecher zu denken. Er redet den Toten an - Kategorie 1b - und zeigt sich dabei stark involviert:

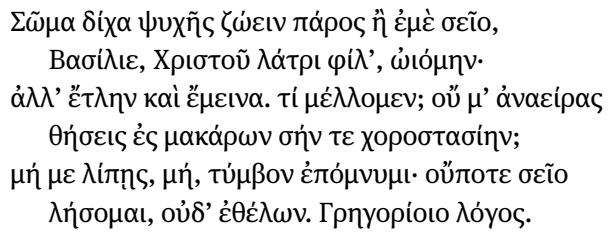

\begin{abstract}
Dass ein Körper ohne Seele leben könnte, wäre, so glaubte ich, eher möglich als ich ohne dich, Basileios, lieber Diener Christi; aber ich habe es ertragen und habe gewartet. Was zögern wir? Wirst du mich nicht nach oben heben und mich nicht in deinen und der Seligen Chor setzen? Verlasse mich nicht, nein, ich schwöre es beim Grab: nie werde ich dich vergessen, auch nicht, wenn ich es wollte. Das ist Gregors Wort.
\end{abstract}

(Greg. Naz. epitaph. 2)

Das Grab als Örtlichkeit der Sprechsituation geht unmittelbar aus der expliziten Be-

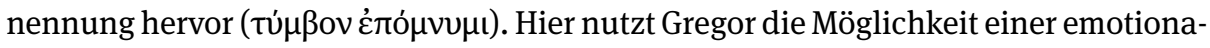
len, subjektiven Sprecherperson am Grab. Die Szene ist dabei in einer Weise dramatisiert, dass man sich das Gedicht eher als ein literarisches denn als ein epigraphisches Epitaphium vorstellen kann. Dabei wird die Trennung durch den Tod in der Sprache der erotischen Dichtung thematisiert. Reminiszenzen an Theognis und Sappho fallen dem gebildeten zeitgenössischen Leser unmittelbar ins Auge. ${ }^{60}$

In epitaph. 3 verwendet Gregor die Einfügung von direkter Rede eines untergeordneten Sprechers. Es entspricht also der letzten Gruppe der Kategorisierung (5):

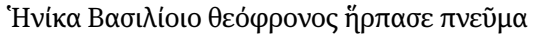

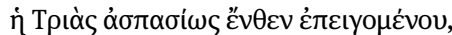

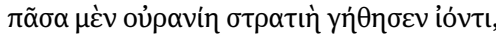

60 Vgl. Consolino 1987, 420 mit Belegstellen. 


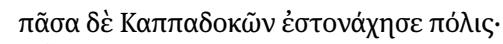

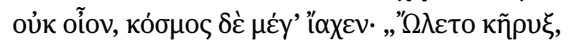

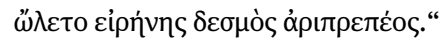

Als die Dreieinigkeit den Atem des göttlich weisen Basileios an sich riss, der freudig von hier eilte, frohlockte das ganze himmlische Heer über den Ankommenden, die ganze Gemeinschaft der Kappadokier hingegen seufzte; und nicht nur das, der Kosmos schrie gewaltig auf: „Der Herold ist gestorben, gestorben das Band des herrlichen Friedens.“

(Greg. Naz. epitaph. 3)

Der Klageschrei des gesamten Kosmos vollzieht sich als ein Sprechakt im Text des Epitaphs ganz konkret. Indem die Äußerung über den Verlust in wörtlicher Rede präsentiert wird, erhält sie besondere Ausdruckskraft. Stellt bereits der Epigrammtext als ganzer die mündliche Äußerung eines Sprechers dar, gewinnt eine in diese eingefügte Rede nochmals besondere Expressivität. ${ }^{61}$ Zunächst beschreibt der übergeordnete

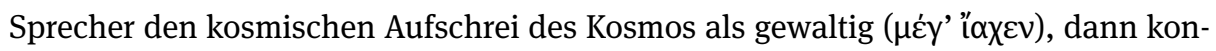
kretisiert sich dieser in Form der eingefügten wörtlichen Rede. Diese Emphase kann dann wiederum von der Ebene des Epigramms auf den Leser wirken. ${ }^{62}$ Die enkomiastische Intention, die Gregor verfolgt, wird effektvoll unterstützt.

In epitaph. 6 ist nun der tote Basileios der Sprecher (Kategorie 2):

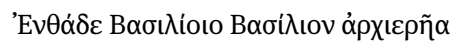

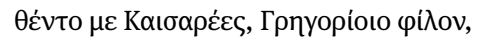

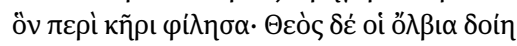

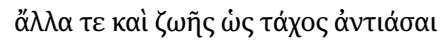

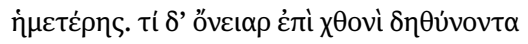

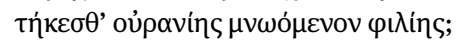

Hier haben mich, des Basileios Sohn Basileios, den Bischof, die Kaisareer beerdigt, den Freund Gregors, den ich von Herzen liebte; Gott möge ihm Segen verleihen, ihm zudem aber auch erlauben, möglichst schnell unseres Lebens teilhaftig zu werden. Was bringt es, auf Erden zu verweilen und sich zu verzehren, wenn man nach der himmlischen Freundschaft strebt?

(Greg. Naz. epitaph. 6)

In diesem Gedicht bewirkt die aus der inschriftlichen und literarischen Tradition übernommene Fiktion, in der der Tote redet, zwei unterschiedliche Effekte: Zunächst wird das Verhältnis zwischen Bischof und Volk beleuchtet, wenn der Sprecher Basileios damit beginnt, dass die Bewohner von Kaisareia ihn an dieser Stelle begraben hätten. Sodann wird die Freundschaft zwischen Gregor und Basileios thematisiert, nun allerdings aus der Perspektive des Freundes. Insbesondere in der Wechselbeziehung

61 Vgl. Meyer 2005, 167: „Fingierte Mündlichkeit [...] dient der Verlebendigung des Textes und der Suggestion von Unmittelbarkeit“.

$62 \mathrm{Zu}$ einer vergleichbaren Wirkung von Aufschriften innerhalb der Rede eines Sprechers vgl. Meyer 2005, 42. 
zu epitaph. 2 wird hierdurch die Reziprozität von Freundschaft in die Ausdrucksform der Dichtung überführt. Die poetische Fiktion, in der der Andere in eigenen Worten spricht, bietet hiermit eine ganz besonders eindrückliche literarische Präsentationsweise einer inhaltlichen Thematik. Am Beispiel des Freundschaftsthemas tritt ganz klar der Mehrwert zutage, den Gregor mit der epigrammatischen Form gegenüber einer Darstellung etwa in einem rednerischen Text erlangt - einer Form, in der Gregor ebenfalls in enkomiastischer Intention über Basileios schreibt. Diese ist allerdings grundsätzlich an den Redner als Sprecher gebunden. Noch einen weiteren Effekt kann Gregor hier über die literarische Form des Epitaphs erzielen: ganz nebenbei fügt er im Munde eines anderen einen Segenswunsch auf sich selbst ein - auch diese Möglichkeit ist nur in der fiktionalen Sprecherfunktion des Epitaphs gegeben.

Schließlich nutzt Gregor die fiktive Kommunikation zwischen dem Trauernden und dem Toten (Kategorie 1b) zum Ausdruck der christlichen Jenseitsgewissheit, sei es, dass der Sprecher und Betrachter des Grabes, Gregor, in epitaph. 5 den toten Ba-

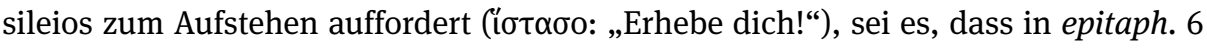
der verstorbene Basileios den trauernden Gregor anspricht und ihm ein Leben nach dem Tod in Aussicht stellt. ${ }^{63}$ So wird die epigraphische und literarische Tradition der fiktiven Kommunikation zwischen Lebenden und Toten mit einem neuen, spezifisch christlichen Gehalt gefüllt.

In der Anthologia Palatina sind 53 Epitaphien Gregors auf seine Mutter Nonna überliefert. Sie geben durchwegs hohen literarischen Anspruch zu erkennen, der sich an einem großen Reichtum an Anspielungen bemessen lässt. ${ }^{64}$ Die erstaunlich große Anzahl an Gedichten auf die Mutter legt nahe, dass der Kirchenvater mit diesen mehr beabsichtigt haben muss, als eine Aufschrift für einen Grabstein oder eine Grabstele zu verfassen. In den einzelnen Gedichten werden verschiedene Aspekte eines vorbildhaften Lebensmodus einer christlichen Frau beleuchtet. Eigenschaften einer idealen Mutter zeigt Gregor in epitaph. 30 auf. Um diese effektiv visualisieren zu können, greift er auf eine hierzu geeignete Darstellungsform zurück. Er nutzt die Möglichkeit der szenischen, mimetischen Ausgestaltung eines Epigramms, indem er die Äußerung eines untergeordneten Sprechers einfügt (Kategorie 5):

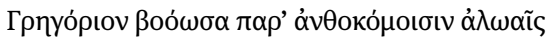

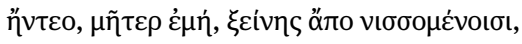

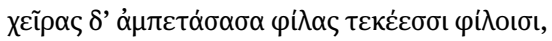

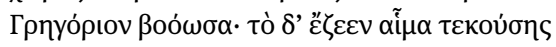

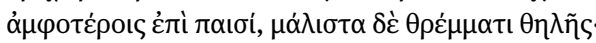

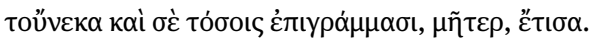

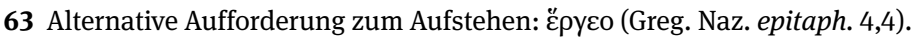
64 Aufgezeigt in den Analysen von Conca 2000, 50-61. 
„Gregor“ riefst du beim blumengeschmückten Garten und kamst entgegen, meine Mutter, uns, die wir aus der Fremde zurückkehrten, und breitetest deine geliebten Arme aus für deine geliebten Kinder und riefst: „Gregor“. Das Blut der Mutter geriet in Wallung über die beiden Kinder, ganz besonders über dasjenige, das sie an ihrer Brust genährt hatte: Deshalb habe ich dich, Mutter, mit so vielen Epigrammen geehrt.

(Greg. Naz. epitaph. 30)

Das Verhältnis zur Mutter wird anhand der Erzählung eines Ereignisses beleuchtet. Es handelt sich um eine Szene, in der die Mutter die Kinder, die aus der Fremde zurückkehren, mit offenen Armen empfängt. Die Rückkehrszene wird mit viel Pathos ausgemalt. Der Ruf nach Gregor wird wiederholt. Es wird das Bild einer sich durch ihre Muttergefühle auszeichnenden Frau entworfen. Der Sprecher redet von einer großen Menge an Epigrammen auf seine Mutter und begründet durch diese große Anzahl, die der Leser der Gedichtsammlung infolge seiner Lektüre selbst bestätigen kann, die herausragende Bedeutung der Mutter.

Szenische Züge trägt auch epitaph. 47 (Kategorie 5). Zum vollen Verständnis dieses Textes muss vorausgeschickt werden, dass Nonna an der Stelle, an der sie begraben ist, auch gestorben war. Dieser Zusammenhang ist dem Leser durch die vorausgehenden Epitaphien bekannt:

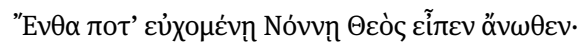

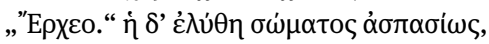

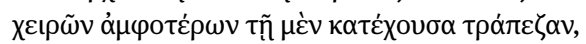

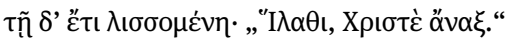

An dieser Stelle sagte einst Gott zu der betenden Nonna von oben: „Komm!“ Und sie wurde zu ihrer Freude aus dem Körper befreit; mit der einen Hand hielt sie sich noch am Altar fest, mit der anderen flehte sie noch: „Erbarme dich, Christus, Herr.“

(Greg. Naz. epitaph. 47)

In diesem Epitaph wird der Toten in Form einer Darstellung der Sterbeszene gedacht. Diese ist gekennzeichnet durch die Erzählung von Handlung. Es erfolgt eine Anrede an Nonna durch Gott in wörtlicher Rede. Das Geschehen erlangt eine hohe Dynamik: Mit der einen Hand hält sie sich noch am Altar fest, die andere erhebt sie mit flehender Geste. Das Gedicht endet in den Worten Nonnas mit einer Bitte an Christus um Erbarmen. Die Handlung schließt somit emphatisch mit den in direkter Rede zum Ausdruck gebrachten ultima verba. Auch mit der Formulierung der letzten Worte als eine Rede in der Rede nimmt Gregor eine sowohl inschriftliche als auch literarische Tradition des Epitaphs auf. ${ }^{65}$

65 Zur inschriftlichen Tradition vgl. GVI 1204-1208; zur literarischen vgl. das kallimacheische Kleombrotos-Epigramm (Call. Epigr. 53 Asper $=23$ Pf.). 
Eine ganz andere Form der Gestaltung von Grabgedichten zeigt epitaph. 31, das einen Tugendkatalog darstellt:

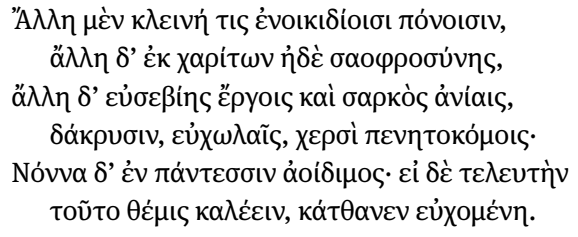

\begin{abstract}
Die eine ist berühmt für ihre Mühen im Haus, die andere für ihren Liebreiz und ihre Sittsamkeit, wieder eine andere für die Werke ihrer Frömmigkeit und die Kasteiungen ihres Fleisches, für ihre Tränen, ihre Gebete, ihre Hände, die arme Menschen pflegen: Nonna wird für all dies gepriesen; und wenn man dies ihr Ende nennen darf: Sie ist beim Beten gestorben.

(Greg. Naz. epitaph. 31)
\end{abstract}

Dieses Gedicht steht in der Tradition einer sehr gängigen Machart von Epitaphien auf Frauen. ${ }^{66}$ Epigraphische Untersuchungen zum paganen Rom haben gezeigt, dass zwar mehr Grabinschriften auf Männer aufgefunden werden können, dass die Gräber von weiblichen Verstorbenen jedoch eine größere Fülle an biographischen Angaben und ausführlichere Charakteristiken aufweisen. ${ }^{67}$ Diese seit der republikanischen Zeit feststellbare Tendenz verstärkt sich in der Kaiserzeit und der Spätantike noch. ${ }^{68}$

Wie lassen sich diese Bedeutsamkeit und diese besondere Art der Gestaltung von Epitaphien auf Frauen erklären? Das Textmedium des Epitaphs war eine der wenigen Möglichkeiten, Tugenden von Frauen, deren Handlungsraum in der Regel auf das eigene Haus beschränkt blieb, öffentliche Sichtbarkeit zu verleihen. ${ }^{69}$ Die dargestellten Eigenschaften fügen sich jedoch stets in einen bestehenden Normenkodex ein, der auf Grabinschriften immer wieder von neuem abgerufen wird. Diese Beobachtung lässt natürlich Zweifel daran aufkommen, ob solche Darstellungen überhaupt als individuelle Charakterisierungen aufzufassen sind. Ganz zu trennen von der realen Lebenswelt der Frauen ist die Setzung solcher moralischen Normen jedoch nicht. Denn diese präsentieren Verhaltensmaßstäbe, denen die Frauen gerecht werden sollen, und die Vermutung ist durchaus berechtigt, dass solche Erwartungshaltungen das tägliche Leben von Frauen entscheidend bestimmt haben. Durch die Grabinschrift wird nun der Verstorbenen bescheinigt, diesen Verhaltenskodex erfüllt zu haben. Die große Bedeutung, die somit Epitaphien auf Frauen erlangen konnten, darf sicherlich auch als

66 Vergleichbar auch Greg. Naz. epitaph. 161 auf Emmelion.

67 Vgl. Wilkinson 2015, 61. Speziell zur Minderzahl von metrischen Inschriften auf Frauengräbern Wolff 2000, 88.

68 Lattimore 1942, 299-300 erklärt diese Entwicklung durch einen Bedeutungsgewinn des Privaten gegenüber dem Staat in der Kaiserzeit infolge der Konzentration der Macht beim Herrscher.

69 Vgl. Wilkinson 2015, 61. 
Erklärung dafür herangezogen werden, dass Gregor gerade auf seine Mutter Nonna diese beträchtliche Anzahl an Grabinschriften verfasst.

Epitaph. 31 umfasst eine Aufzählung weiblicher Tugenden, die in einer Überbietungsformel dargebracht werden. Die Tugendbegriffe werden hier in einer Anordnung präsentiert, in der sich die historische Entwicklung dieses Epitaphientypus widerspiegelt. ${ }^{70}$ Das Gedicht formuliert die Grundannahme, dass Frauen über die Möglichkeit

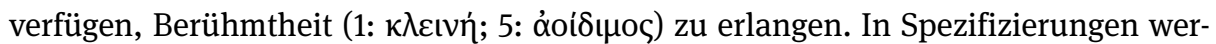
den verschiedene Bereiche angeführt, in denen diese Option gegeben ist (1-2: 'A $\lambda \lambda \eta$

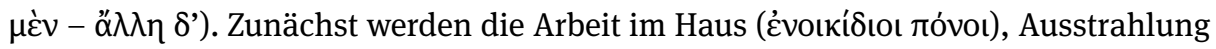

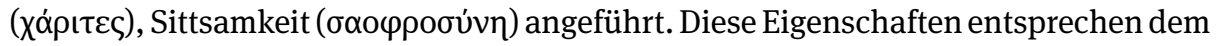
seit der paganen Zeit geltenden Wertehorizont. Darauf folgen in einer zweiten Gruppe zusammengefasst (3-4: $\alpha \beta \lambda \lambda \eta \delta^{\prime}$ ) spezifisch christliche Normen. Hierbei wird auf ihre

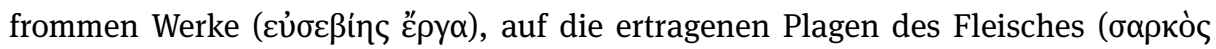

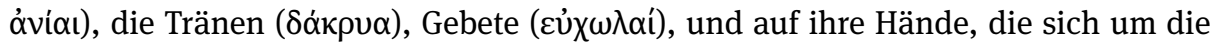

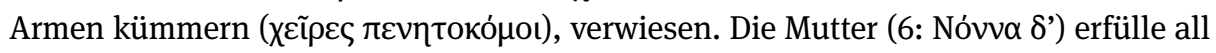
diese Eigenschaften, überbiete sie aber durch ihren Tod im Gebet, der als Ausweis ihrer Frömmigkeit erscheint. Die Charakteristik lässt somit drei Ebenen erkennen: Der traditionell-pagane Tugendkatalog (1) wird um einen christlichen (2) erweitert. Der Erfüllung dieses allgemeinen Normenhorizonts, den inschriftliche Epitaphien gewöhnlich abdecken, wird hier noch eine individuelle Tat (3) als Überbietung hinzugefügt. ${ }^{71}$

Herauszuheben sind über die bisher aufgezeigten Formen des Grabepigramms Epitaphien, in denen die Heimatstadt (z. B. in Greg. Naz. epitaph. 135 die Stadt Dioskaireia als Herkunftsort des Redners Amphilochios) oder Mitbürger (z. B. Greg. Naz. epitaph. 113) als Sprecher fungieren. Diese knüpfen an die Tradition offizieller Epitaphien auf verdiente Bürger an. ${ }^{72}$ Eine breite Variation an Sprecher- und Adressatenrollen bieten auch die Epigramme gegen Grabschänder, die vom Toten, vom Grab oder einem nicht klar bestimmbaren Sprecher gesprochen sein können. Wird die gleiche Ermahnung von so vielen unterschiedlichen Sprecherfiguren ausgesprochen, kann dahinter eine Aussage des Autors vermutet werden. Abwechslung gibt es nicht nur bei den Sprechern, sondern auch bei den Adressaten, so dass die Epigramme eine Warnung ausdrücken können, wenn ein potentieller Grabräuber angesprochen wird, oder einen Hilferuf, wenn ein anonymer Passant adressiert wird.

70 Zum Grabepigramm als Träger von Wertvorstellungen der jeweiligen Zeit vgl. Meyer 2005, 65 (über Athen im 4. Jh. v. Chr.); zur Ergänzung paganer Normen um christliche in der Traditionsgeschichte des meist in Prosa abgefassten Epitaphs vgl. Trout 2013, 20-21.

71 Es finden sich weitere Epitaphien, in denen ebenfalls Nonna als Ideal einer Mutter dargestellt wird: In Greg. Naz. epitaph. 36 beschwichtigt sie durch ihr Gebet für die Kinder das Meer und erweist

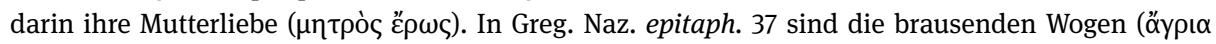

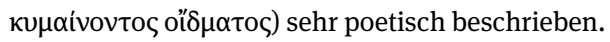

72 Der berühmteste dieser Staatsepitaphien ist der Epitaphios der Perikles auf die gefallenen Athener bei Thukydides. 


\section{Die literarische Funktion der Epitaphien}

Abschließend stellt sich die Frage nach der literarischen Funktion der Grabepigramme Gregors. Die Epitaphien sind nicht als Konsolationsliteratur im engeren Sinne aufzufassen. Ein Unterschied zu den consolationes ist insofern gegeben, als in den Epitaphien dem Leser kein Trost gespendet wird und auch keine Anweisungen für den Umgang mit Trauer gegeben werden. ${ }^{73}$ Dennoch gliedern sie sich in den Kontext einer Trauerliteratur im weiteren Sinne ein, da in ihnen der Sprecher seine subjektive Erfahrung darstellt und dabei eine exemplarische Verarbeitung seiner Trauer vollzieht. Hierin ergänzen sich die Epitaphien Gregors mit seinen Grabreden. ${ }^{74}$

Indem Gregor die Epitaphien zu einem Kollektiv von Gedichten zusammenstellt, nimmt er die schon seit der Zeit des Hellenismus bestehende literarische Tradition der Epigrammsammlung auf. Während sich aber bereits bei Kallimachos Epitaphien finden, die dem literarischen Selbstzweck dienen, weicht Gregor von dieser Tradition insofern ab, als er die Epitaphien wieder ihrer ursprünglichen Funktion im Kontext der Memorialkultur zuweist. Hierbei nutzt Gregor die Vielzahl an kommunikativen Formen, in der sich die Sprecher-Adressaten-Beziehung verwirklichen kann, um in alternativer literarischer Form eine enkomiastische und paränetische Intention zu verfolgen, auf die er auch in zahlreichen anderen Werken abzielt. Für den Bruder Kaisarios (Greg. Naz. or. 7), die Schwester Gorgonia (or. 8) sowie den Vater Gregor (Greg. Naz. or. $18^{75}$ ) schrieb er Grabreden. Seine Mutter Nonna können wir insbesondere in seinem autobiographischen Gedicht De vita sua fassen. Die Epitaphien korrelieren mit biographischen Porträts, die in anderen Werken gezeichnet werden und dort ebenfalls dazu dienen sollen, die Personen zum einen zu loben und sie zum anderen als exempla einer vorbildhaften christlichen Lebensweise oder einer ideal geführten Freundschaft zu präsentieren. ${ }^{76}$ Das Enkomium ist somit nicht Endzweck, sondern wird einer Zielsetzung im Sinne des christlichen Glaubens untergeordnet.

\section{Zusammenfassung}

Fassen wir die zu Gregor erzielten Erkenntnisse kurz zusammen: Gregor nimmt ein breites Spektrum von Gestaltungsformen auf, die für Stein- und Buchepitaphien gängig sind, und führt sie zusammen. Eine solche literarische Technik steht in der Tradition der hellenistischen und kaiserzeitlichen Epigrammsammlungen, die ebenfalls

73 Zur Differenzierung zwischen einer generellen und einer speziellen Auffassung von Konsolationsliteratur vgl. die Definition bei Kierdorf 1999, 709.

74 Zu Greg. Naz. or. 7,18-21 und epist. 223 vgl. Mitchell 1968.

75 Vgl. ferner Gregors autobiographisches Gedicht De vita sua 51-56.

76 Zur Mutter Nonna vgl. Greg. Naz. or. 18,7-11, De vita sua 57-67, epist. 7,7. 
eine Mischung verschiedener Epigrammtypen und eine Variation der Sprecher verfolgten. Epigrammzyklen einzelner Dichter oder Anthologien aus mehreren Autoren, etwa die des Meleagros von Gadara (ca. 130 - ca. 70 v. Chr), weisen Zusammenstellungen von Gedichten auf, hinter denen sich eine programmatisch verfolgte Variation bestimmter Themen erkennen lässt. Eine solche Abwechslung kann die Diversität von Liebeserfahrungen beleuchten (Meleager) oder die Ablehnung der Vorstellung eines Lebens nach dem Tod in verschiedener Weise thematisieren (Kallimachos). ${ }^{77}$ Die Literarisierung des Epitaphiums hat für die Gattung zur Folge, dass die ursprüngliche Funktion der Herstellung eines Gedenkens an einen spezifischen Toten nicht mehr erfüllt werden muss. Die Loslösung des Grabepigramms von seiner materiellen Basis und die Einfügung in das Ensemble einer Sammlung hat gewissermaßen zu einer Entfesselung des Epigramms geführt und sogar den Schritt zur ironischen Brechung ermöglicht.

Gregor fügt sich durchaus in die Tradition der literarischen Epigrammsammlung ein. Allerdings muss als Unterschied festgestellt werden, dass seine Epitaphien den Steinepigrammen darin näherstehen, dass sie durch das Gedenken an eine konkrete verstorbene Person weiterhin der ursprünglichen sozialen Funktion im Kontext der Memorialkultur verhaftet bleiben. Hierbei führt er nicht nur das Einzelepigramm an seinen originären ,Sitz im Leben' zurück, sondern unterwirft auch die Epigrammsammlung als ein Ganzes dieser Bestimmung. Das Totengedenken wird dabei nicht um seiner selbst willen vollzogen, sondern ist ein Medium zur Vermittlung weiterer theologischer Aussagen. Dabei nutzt Gregor die durch das Ensemble entstehenden Bezüge und die Vielzahl an möglichen kommunikativen Konstellationen, in denen sich der Sprecher wiederfinden kann: um ein Bild der Beziehung zu seinem Freund Basileios zu zeichnen, in dem dieses Verhältnis als ein Ideal von Freundschaft erscheint, oder um Nonna in unterschiedlichen Zusammenhängen und unter Betrachtung verschiedener Facetten als eine beispielhafte christliche Frau zu präsentieren.

Bei Gregor wird zum einen erkennbar, dass die Ensemblebildung das Bedeutungspotential eines Epitaphiums im Verhältnis zum inschriftlichen Einzelepigramm deutlich erweitert, da es nun in einen intratextuellen Bezug zu anderen Gedichten der Sammlung tritt. Die Epitaphien verdichten sich in einer gattungstypologisch homogenen Sammlung zu einer vielseitigen Betrachtung der einzelnen Personen. Im Kontext des literarischen Schaffens Gregors bildet das Epitaph eine literarische Darstellungsform mit Mehrwert, die Ausdruckmöglichkeiten bietet, die andere Gattungen wie Rede oder Brief nicht kennen. Die formale und thematische Variation legt nahe, dass Gregor von Anfang an eine Publikation als Textsammlung vorschwebte. Die Gedichte

77 Vgl. Gutzwiller 1998, 183-226, 229-230 sowie 301 zusammenfassend zu Meleager und der erotischen Thematik: „The effect of this polyphony was to present a variety of points of view, which yet together suggest the uniformity or universality of erotic experience." $\mathrm{Zu}$ den Grabepigrammen des Kallimachos vgl. Braun 1986, 69: „Non sono mai ordinari, mai triviali, ma ogni epigramma svolge il suo tema in una maniera diversa, sempre originale.“ 
verfolgen eine enkomiastische Intention. Im christlichen Sinne zielen die Gedichte jedoch nicht auf die selbstzweckhafte Verherrlichung von Personen, sondern auf die Darstellung ihrer Exemplarität ab. Somit können sie auch eine paränetische Wirkung erzielen.

Gregor führt das Grabepigramm, nachdem es durch die Loslösung von seiner ursprünglichen materiellen Basis und durch den Übergang in das Ensemble von Gedichtsammlungen seine Funktion im Kontext des Totengedenkens verloren hat, nun wieder zu seiner eigentlichen Bestimmung als Element der Memorialkultur zurück. Dies tut der Dichter und Theologe nun aber nicht, indem er einen Schritt in der Gattungsentwicklung des Epigramms zurück macht. Vielmehr bestimmt er das Epitaphium als Buchepigramm im Zusammenhang einer Gedichtsammlung, die kaleidoskopartig unterschiedliche Gestaltungsformen sowohl aus der inschriftlichen als auch schriftlichen Tradition zusammenführt. Damit schafft er eine nicht mehr ortsgebundene, sondern eine literarische Form des christlichen Totengedenkens, die einen weiteren Rezipientenkreis erreichen kann. Durch eine solche neue Zwecksetzung macht Gregor die Epigrammsammlung, die in der paganen Literatur seit dem Hellenismus weitgehend dem ästhetischen Genuss diente, zu einer Form der christlichen Literatur.

\section{Literaturverzeichnis}

Agosti, Gianfranco (2008), „Literariness and Levels of Style in Epigraphical Poetry of Late Antiquity“, in: Ramus 37, 191-213.

Agosti, Gianfranco (2010a), „Saxa loquuntur? Epigrammi epigrafici e diffusione della paideia nell'oriente tardoantico“, in: Antiquité tardive 18, 163-180.

Agosti, Gianfranco (2010b), „Paideia classica e fede religiosa: annotazioni sul linguaggio dei carmi epigrafici tardoantichi“, in: Cahiers du Centre Gustave Glotz 21, 329-353.

Agosti, Gianfranco (2015), „Per uno studio dei rapporti fra epigrafia e letteratura nella tarda antichità“, in: Lucio Cristante u. Tommaso Mazzoli (Hgg.), Il calamo della memoria. Riuso di testi e mestiere letterario nella tarda antichità VI (Polymnia. Studi di filologia classica 10), Trieste, 13-33.

Asper, Markus (2004), Kallimachos. Werke. Griechisch und deutsch, hg. und übers. von M. A., Darmstadt.

Beckby, Hermann (1957), Anthologia Graeca. Band 2: Buch VII-VIII. Griechisch-Deutsch, hg. von H. B., München.

Bettenworth, Anja (2007), „The Mutual Influence of Inscribed and Literary Epigram“, in: Peter Bing u. Jon Steffen Bruss (Hgg.), Brill's Companion to Hellenistic Epigram (Brill's Companions in Classical Studies), Leiden/Boston/Köln, 69-93.

Braun, Ludwig (1986), „L'arte di Callimaco negli epigrammi funerari“, in: Studi classici e orientali 35, 57-70.

Buecheler, Franciscus (1895/1897), Anthologia Latina II: Carmina Latina Epigraphica, 2 Fasc., Lipsiae (= CLE).

Cameron, Alan (1993), The Greek Anthology from Meleager to Planudes, Oxford.

Conca, Fabrizio (2000), „Gli epigrammi di Gregorio Nazianzeno“, in: Koinonia 24, 47-66. 


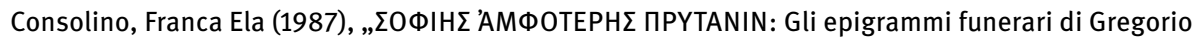
Nazianzeno (AP VIII“), in: Athenaeum 75, 407-425.

Criscuolo, Ugo (2007), „Sugli epigrammi di Gregorio di Nazianzo“, in: Giuseppe Lozza u. Stefano Martinelli Tempesta (Hgg.), L'epigramma greco. Problemi e prospettive (Quaderni di Acme 91), Mailand, 19-52.

Degani, Enzo (1997), „Epigramm. I. Griechisch“, in: Der Neue Pauly 3, 1108-1112.

Floridi, Lucia (2013), „The Epigrams of Gregory of Nazianzus Against Tomb Desecrators and Their Epigraphic Background“, in: Mnemosyne 66, 55-81.

Garulli, Valentina (2012), Byblos lainee. Epigrafia, letteratura, epitafio (Eikasmos Studi 20), Bologna.

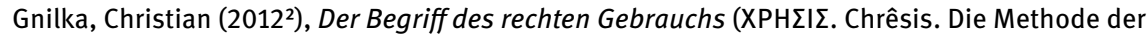
Kirchenväter im Umgang mit der antiken Kultur 1), Basel.

Gutzwiller, Kathryn J. (1998), Poetic Garlands. Hellenistic Epigrams in Context (Hellenistic Culture and Society 28), Berkeley/Los Angeles/London.

Hall, John B. (1985), Claudii Claudiani carmina, hg. von John B. Hall, Leipzig.

Harich-Schwarzbauer, Henriette (2009), „Prodigiosa silex. Serielle Lektüre der Carmina minora Claudians“, in: Henriette Harich-Schwarzbauer u. Petra Schierl (Hgg.), Lateinische Poesie der Spätantike. Internationale Tagung in Castelen bei Augst, 11.-13. Oktober 2007 (Schweizerische Beiträge zur Altertumswissenschaft 36), Basel, 11-31.

Holzberg, Niklas (2012²), Martial und das antike Epigramm. Eine Einführung, Darmstadt.

Hutchinson, Gregory 0. (1988), Hellenistic Poetry, Oxford.

Kierdorf, Wilhelm (1999), „Konsolationsliteratur“, in: Der Neue Pauly 6, 709-711.

Lattimore, Richmond (1942), Themes in Greek and Latin Epitaphs (Illinois Studies in Language and Literature 28.1-2), Urbana (IL).

Merkelbach, Reinhold/Stauber, Josef (1998-2004), Steinepigramme aus dem griechischen Osten, 5 Bde., Stuttgart/Leipzig.

Meyer, Doris (2005), Inszeniertes Lesevergnügen. Das inschriftliche Epigramm und seine Rezeption bei Kallimachos (Hermes Einzelschriften 93), Stuttgart.

Mitchell, Jane F. (1968), „Consolatory Letters in Basil and Gregory Nazianzen“, in: Hermes 96, 299-318.

Peek, Werner (1955), Griechische Vers-Inschriften, Band 1: Grab-Epigramme, Berlin.

Reitzenstein, Richard (1907), „Epigramm“, in: Realencyclopädie der classischen Altertumswissenschaft VI.1, 71-111.

Schmitz, Thomas A. (2010), „Epigrammatic Communication in Callimachus’ Epigrams“, in: Greek, Roman and Byzantine Studies 50, 370-390.

Schultheiß, Jochen (2011), Generationenbeziehungen in den Confessiones des Augustinus. Theologie und literarische Form in der Spätantike (Hermes Einzelschriften 104), Stuttgart.

Sklenár̆, Robert (2003), „The Cosm(et)ology of Claudian's In Sepulcrum Speciosae“, in: Harvard Studies in Classical Philology 101, 483-487.

Trout, Dennis (2013), „Fecit ad astra viam: Daughters, Wives, and the Metrical Epitaphs of Late Ancient Rome“, in: Journal of Early Christian Studies 21, 1-25.

Waltz, Pierre (21960), Anthologie Grecque, Première partie. Anthologie Palatine, Tome VI. Livre VIII, hg. und übers. von P. W., Paris.

Wilkinson, Kate (2015), Women and Modesty in Late Antiquity, Cambridge.

Wolff, Étienne (2000), La poésie funéraire épigraphique à Rome, Rennes.

Wulfram, Hartmut (2008), Das römische Versepistelbuch. Eine Gattungsanalyse, Berlin.

Wyss, Bernhard (1949), „Gregor von Nazianz. Ein griechisch-christlicher Dichter des 4. Jahrhunderts“, in: Museum Helveticum 6, 177-210. 


\section{Anhang}

Tab. 1: Kategorisierung der Sprecher- und Adressatenrollen in den Epitaphien Gregors von Nazianz ${ }^{78}$

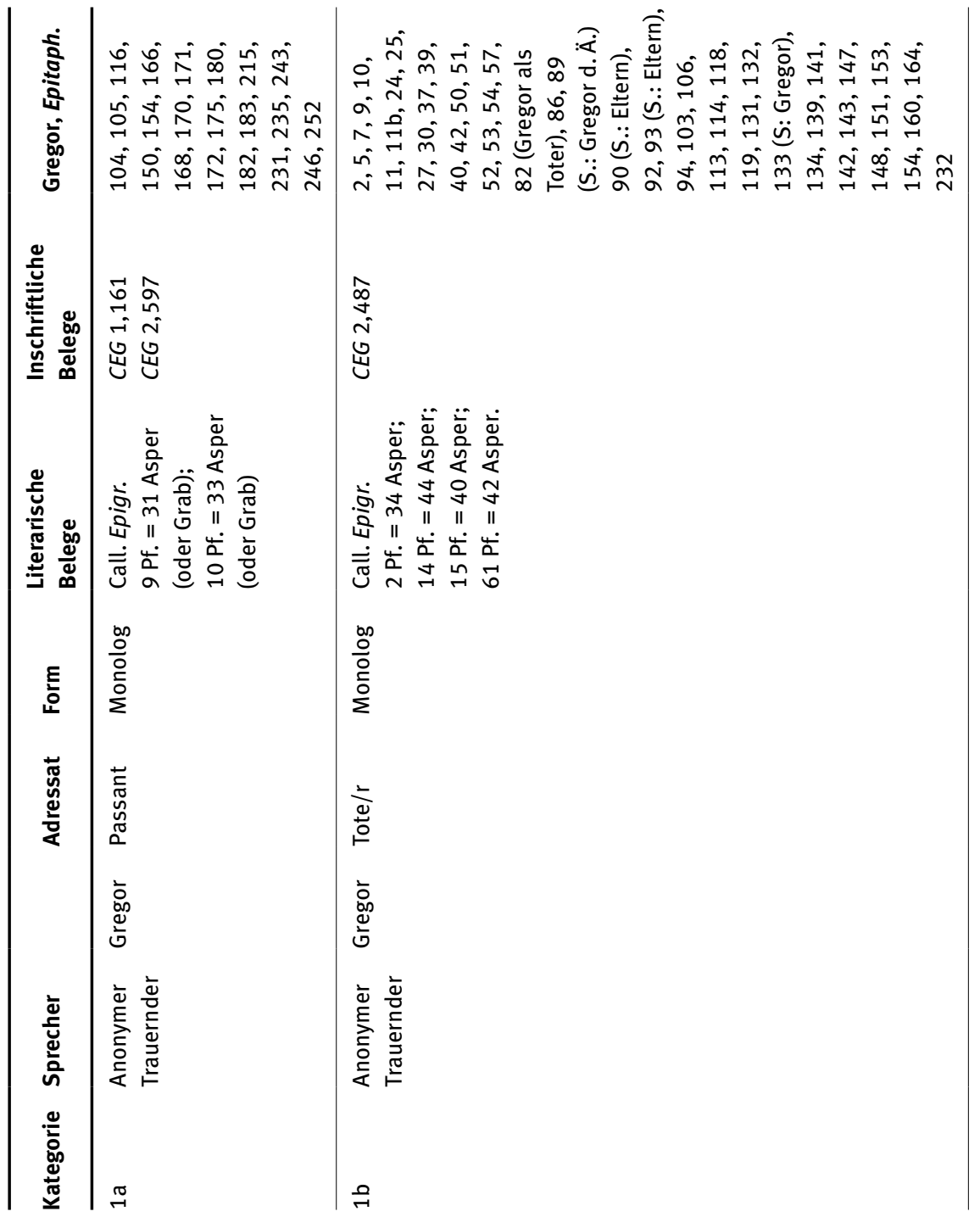

78 Bei der Angabe von Belegen aus der literarischen und inschriftlichen Tradition kann die Tabelle im Rahmen dieser Arbeit keine Vollständigkeit anstreben. Vielmehr sollen die Angaben anhand von Beispielen dem Beleg dienen, dass Gregor von Nazianz sich in der Gestaltung seiner Epitaphien an geläufigen Gestaltungsformen orientiert. Bei den Angaben zu Kallimachos bot Meyer 2005, 148-151 hilfreiche Orientierung. 
Tab. 1: fortgesetzt.

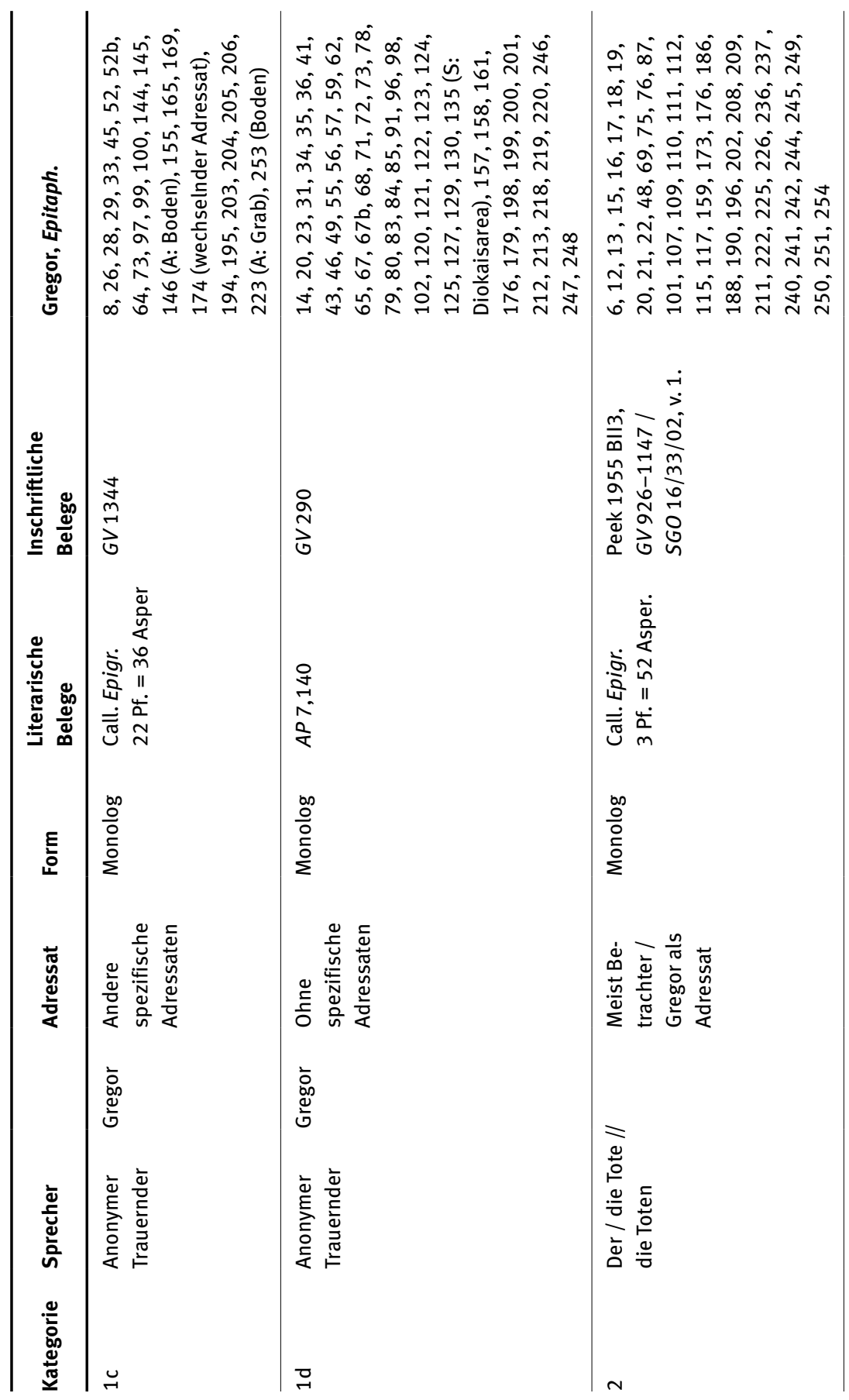


Tab. 1: fortgesetzt.

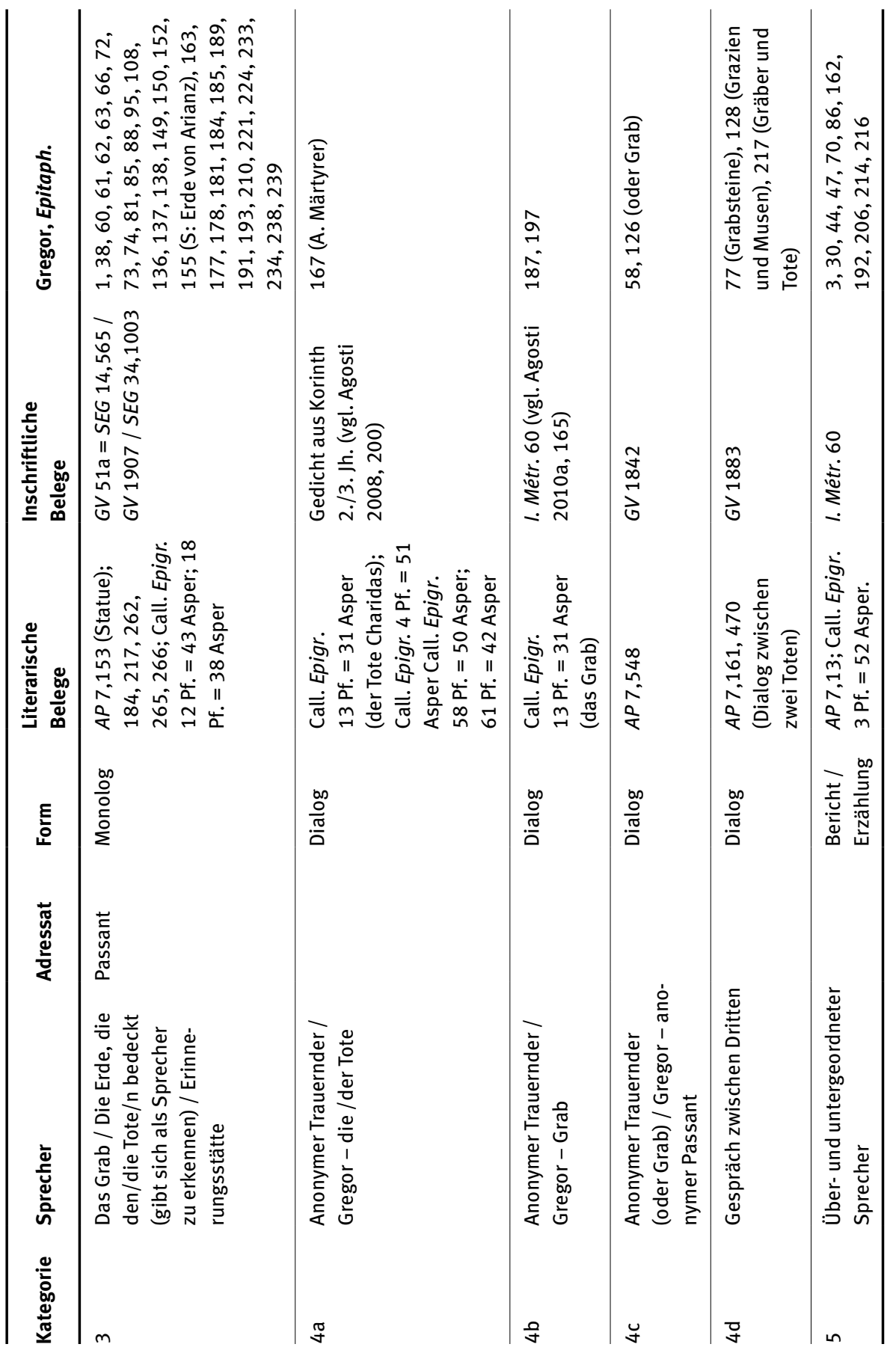

